\title{
MegAPROYECTOS A CONSULTA: ¿DERECHOS O SIMULACIONES? EXPERIENCIAS EN MÉXICO
}

\section{Megaprojects in Consultation: Rights or Simulations? EXPERIENCES IN MEXICO}

\author{
Giovanna Gasparello* \\ DOI: https://doi.org/10.29043/liminar.vl8i2.762
}

\begin{abstract}
Resumen: Desde hace décadas, los megaproyectos extractivos y de infraestructura son impuestos por gobiernos y empresas, lo que menoscaba las prioridades de las poblaciones que viven en los territorios afectados. Actualmente, la legislación que protege los derechos de los pueblos indígenas respalda el derecho a la consulta previa, libre e informada. El objetivo de este ensayo es discutir oportunidades y riesgos en los procesos de consulta a los pueblos indígenas a partir de la observación y el análisis de algunos casos paradigmáticos en México, entre ellos los más recientes como el Tren Maya y el Corredor Transístmico.
\end{abstract}

Palabras clave: pueblos indígenas, derecho a la consulta, libre determinación, territorios indígenas, megaproyectos.

\begin{abstract}
For decades, governments and companies have forced through extractive and infrastructure megaprojects, undermining the priorities of people living in the affected territories. Currently, legislation exists that protects indigenous people's right to prior, free, and informed consultation. The objective of this article is to discuss opportunities and risks of consultations held with indigenous peoples, based on the observation and analysis of some paradigmatic cases in Mexico. Among the most recent are the Mayan Train and the Trans-Isthmus Corridor.
\end{abstract}

Keywords: indigenous peoples, right of consultation, self-determination, indigenous territories, megaprojects.

\footnotetext{
* Giovanna Gasparello. Doctora en Ciencias Antropológicas por la Universidad autónoma Metropolitana-Iztapalapa, México. Profesorainvestigadora titular B, Dirección de Etnología y Antropología Social, Instituto Nacional de Antropología e Historia, México. Temas de especialización: derechos indígenas, antropología jurídica, megaproyectos y defensa de los territorios. Correo electrónico: giovanna. gasparello@libero.it. ORCID: https://orcid.org/0000-0001-8170-0073
}

\author{
Enviado a dictamen: 19 de agosto de 2019 \\ Aprobación: 30 de febrero de 2020 \\ Revisiones: 1.
}




\section{Introducción}

$\mathrm{D}$ esde hace décadas, los megaproyectos extractivos y de infraestructura son impuestos por gobiernos y empresas, que los justifican bajo el argumento del beneficio público que traerán consigo, pero que menoscaban las prioridades expresadas por las poblaciones que viven en los territorios afectados.

Los emprendimientos extractivos, deinfraestructura, turísticos o agroindustriales que se caracterizan por su magnitud e intensidad, y por su impacto humano y social, son considerados "proyectos de gran escala" (Lins, 1987) o "megaproyectos" y generan importantes afectaciones para las personas que habitan en los territorios objeto de la intervención. Algunos ejemplos de estos impactos son: la pérdida de tierra y territorios tradicionales; la migración, el desalojo y el reasentamiento; el agotamiento de los recursos necesarios para la supervivencia física y cultural; la destrucción y contaminación del medioambiente; la fragmentación del tejido social comunitario, y el hostigamiento y la violencia.

En el contexto global actual, y específicamente en México, el renovado impulso a la realización de megaproyectos viene acompañado de un incremento generalizado de la presión sobre los territorios indígenas y campesinos por pequeños y grandes emprendimientos cuyo común denominador es la codicia por los bienes comunes que hasta este momento conservan sus habitantes, en aquellas que Aguirre Beltrán (1991) definió regiones de refugio por su carácter marginal en términos geográficos y sociales. La voracidad hacia los territorios y sus riquezas responde en parte a la reprimarización de la economía a nivel continental, y en parte a la ambición capitalista de que espacios y población hasta este momento marginales o no completamente integrados a la economía de mercado se incorporen al mecanismo de producción de servicios/ consumo de mercancías.

Frente a esta situación, que afecta a grandes sectores de población rural, asistimos a una creciente movilización colectiva para la defensa de los territorios y a un incremento de la conflictividad y de la violencia hacia aquellos sectores que se oponen a los proyectos extractivos. Los pueblos indígenas han tenido un protagonismo sin precedentes en la defensa territorial, para lo que han utilizado la acción directa, la lucha legal y el fortalecimiento de las identidades colectivas arraigadas en el territorio, la cultura y el espacio ritual. La acción en el campo jurídico y el uso de las herramientas legales no son novedades para los pueblos indígenas, que desde la época colonial conocieron y supieron utilizar de manera estratégica el andamiaje legal impuesto para reivindicar, en sus mismos términos, la defensa de los derechos colectivos. Actualmente, el ámbito legal de los procesos de defensa territorial encuentra un poderoso respaldo en el derecho internacional, a partir del cual desde hace tres décadas se han implementado herramientas jurídicas para la protección de los derechos de los pueblos indígenas al territorio y a la cultura. El instrumento más importante, por su carácter vinculante - esto es, de obligatorio respeto por parte de los Estados que lo suscribieron- es el Convenio 169 de la Organización Internacional del Trabajo (OIT, 1989), ratificado por México en 1989 y elevado a rango constitucional en 2011 en lo que corresponde a la garantía de los derechos humanos. Dicho convenio exige el respeto al derecho a la consulta previa, libre e informada a los pueblos indígenas que podrían ser afectados, así como la implementación de mecanismos de mitigación relativos a los impactos ambientales y sociales de los megaproyectos.

El reclamo por el respeto del derecho a la consulta, o eventualmente la denuncia por su violación, aparece como sustento de muchas demandas ligadas a afectaciones territoriales, lo que ha contribuido a que se respetara, así, un argumento estratégico que, en ocasiones y aunado a una fuerte movilización popular, ha logrado detener el desarrollo de agresivos megaproyectos. A raíz de esta situación, en la última década distintas dependencias han sido conminadas o decidieron realizar procesos de consulta, pero sin respetar el objetivo intrínseco de la consultación que implicaría acatar la opinión que de ella emergiera, sino utilizándola como un mecanismo de intervención y manipulación de las sociedades impactadas. 
En particular, el actual gobierno (2018-2024) ha utilizado con frecuencia inédita mecanismos consultivos para legitimar grandes obras de infraestructura y proyectos legislativos que asume como centrales en su Plan Nacional de Desarrollo, por lo que ha enfrentado fuertes críticas tanto desde las organizaciones populares e indígenas, como desde instancias políticas supranacionales como la Organización de las Naciones Unidas.

En tal contexto, es preciso interrogarse en primer lugar sobre los alcances y los límites de la herramienta de la consulta tal y como se está implementando hoy día en México, y, en segundo lugar, sobre la pertinencia de orientar tanto el debate académico como la práctica política hacia la reivindicación de derechos sustantivos más integrales y de más difícil manipulación, como el derecho al territorio y a la libre determinación, que siempre han sido centrales en las reivindicaciones del movimiento indígena desde su aparición a finales de la década de los ochenta.

En este texto abordo la diferencia entre la "consulta ciudadana", la "consulta pública ambiental" y la "consulta previa a los pueblos indígenas", en aras de esclarecer las características específicas y los límites de los mecanismos impulsados desde el gobierno mexicano a lo largo del año 2019. En segundo lugar aporto algunas reflexiones, desde la perspectiva antropológica, sobre el territorio como concepto, derecho y vivencia de los pueblos indígenas, enfatizando la importancia de la dimensión cultural del territorio mismo, identificando así una perspectiva de gran relevancia en las posibles afectaciones por los megaproyectos. Asimismo, expongo una discusión crítica del derecho procesal a la consulta en relación con los derechos sustantivos al territorio y a la libre determinación. Propongo algunas reflexiones sobre riesgos y problemas importantes de los más recientes ejercicios consultivos realizados en México: la consulta ciudadana para la termoeléctrica de Huexca, y las consultas a los pueblos indígenas involucrados en los megaproyectos del Corredor Transístmico y del Tren Maya. Concluyo este trabajo con algunas consideraciones sobre la oportunidad de los procesos de consulta y la importancia de retomar un enfoque más integral hacia los derechos de los pueblos a la autonomía y la libre determinación.

\section{Consulta ciudadana, consulta popular y consulta pública ambiental: mecanismos de gobernanza neoliberal}

El término "consulta" apareció con altísima frecuencia en los medios de comunicación y en el debate político de México durante el año 2019 a partir de que el Ejecutivo guiado por el presidente Manuel López Obrador emprendió el uso frecuente de una forma específica de dicha herramienta para legitimar deliberaciones gubernamentales sobre varios proyectos de infraestructura y legislativos. Sin embargo, existe una notable confusión en la opinión pública sobre las distintas acepciones del término y las diferentes caracterizaciones y atribuciones legales que estas implican.

La oportunidad de proceder con la construcción de megaproyectos de infraestructura como el nuevo aeropuerto de la Ciudad de México en Texcoco, el Tren Maya en el sureste y el Corredor Transístmico entre Oaxaca y Veracruz ha sido sometida por la Presidencia a dos procesos denominados "consulta nacional"1 que se realizaron entre octubre y noviembre de 2018 — cuando el actual Ejecutivo aún no estaba en funciones, pues las consultas fueron convocadas y financiadas por el partido Morena y los futuros gobernantes-. Por su parte, el término y puesta en marcha de la planta termoeléctrica en Huexca - parte del Proyecto Integral Morelos en los estados de Puebla, Tlaxcala y Morelos - ha sido objeto de una "consulta ciudadana” organizada en febrero 2019 por la Secretaría de Gobernación en las tres entidades interesadas, incumpliendo la exhaustiva legislación nacional e internacional sobre las características que debe tener un proceso de consulta cuando los sujetos interesados sean integrantes de un pueblo indígena, como es el caso de esta región, habitada por indígenas nahuas.

Según la jurista Sánchez Cordero, actual titular de la Secretaría de Gobernación [enero de 2020], dichas consultas representan una herramienta política y de 
gobierno ("Sánchez Cordero contradice a AMLO...", 2018), ya que permiten a los gobernantes tener una muestra sobre el nivel de consenso que existe entre la población con respecto a un determinado proyecto o proceso - aunque se trate de muestras no representativas por la relación entre el porcentaje de votantes y el padrón-. Las consultas ciudadanas sirvieron también para legitimar decisiones tomadas por el Ejecutivo, cobijándolas con el respaldo de la voluntad popular. Se trata, sin embargo, de herramientas que carecen de fundamento legal y cuyo resultado por lo tanto no es vinculante, a pesar de que el discurso público del presidente y los funcionarios haya fundamentado en ellas el impulso a las citadas obras de infraestructura.

Un mecanismo distinto es la "consulta popular", contemplada en el artículo 35 de la Constitución mexicana y reglamentada por la Ley Federal de Consulta Popular: es la principal herramienta de participación popular vigente en México (Murayama, 2019). Este tipo de consulta se puede realizar solo durante la jornada electoral federal, esto es, cada seis años, y su organización está a cargo del Instituto Nacional Electoral. Se trata de un proyecto de larga preparación - entre uno y cinco años- y su resultado es vinculante si la participación corresponde al menos al $40 \%$ de los electores. Por el contrario, las consultas realizadas entre 2018 y 2019 han sido convocadas con un lapso de entre cuatro días y tres semanas de anticipación.

El Instituto Electoral y de Participación Ciudadana de Yucatán señaló a principio de 2019 que la consulta popular podría ser solicitada por los municipios - alcaldes y pobladores - interesados por el trazo del Tren Maya, y realizarse en la jornada electoral de 2021. Sin embargo, en diciembre de 2019, mediante un decreto presidencial se añadió una nueva acotación a esta herramienta: ahora "no podrán ser objeto de consulta popular [...] las obras de infraestructura en ejecución" ("Decreto por el que se declara reformadas...", 2019: art. 35). Por lo tanto, si se considera que la ejecución de una obra inicia desde el otorgamiento de contratos a empresas para su planeación y realización, queda de manifiesto que una obra como el Tren Maya ya no podrá ser sometida al mecanismo de consulta popular. La medida resulta en sí contradictoria con las acciones emprendidas por el Ejecutivo, como aquella de someter a "consulta nacional" - herramienta política- la terminación del aeropuerto de la Ciudad de México en Texcoco, obra en construcción avanzada. Ese proceso, sin fundamento legal, convocado por el Ejecutivo, permitió legitimar la decisión de cancelar la obra y atender las legítimas demandas de los pueblos originarios del valle de Texcoco. Sin embargo, una análoga solicitud, pero por parte de la población, ya no tendría una herramienta legal para llevarse a cabo.

Cualquier proyecto, obra o actividad susceptible de tener un impacto ambiental, como es el caso de los megaproyectos, también puede ser objeto de una "consulta pública ambiental", recurso contenido en la Ley General del Equilibrio Ecológico y la Protección al Ambiente (art. 34). Este mecanismo de participación permite a cualquier ciudadano solicitar que se realice una consulta pública sobre una "manifestación de impacto ambiental" ya emitida en relación con alguna obra o proyecto, y al igual que la consulta a pueblos indígenas se tiene que realizar en una fase previa a la obra — en el marco del procedimiento de evaluación de impacto ambiental-

Esta forma de consulta representa, en términos de principio, una herramienta participativa importante para la población no indígena que habita en los territorios interesados por las obras y proyectos, incluso en las zonas urbanas. Sin embargo, la consulta pública ambiental adolece de las mismas fallas que muchos mecanismos de "participación ciudadana", cuyo auge creciente los denota como arreglos políticos que buscan compensar las falacias de la democracia representativa, pues permiten a los ciudadanos presentar objeciones y propuestas en aras de influenciar sobre las decisiones de los gobernantes (Henríquez, 2013), pero no tienen carácter deliberativo o de toma de decisiones. Por esto, la realización de dicha consulta es optativa por parte de las autoridades - que no tienen la obligación de atender la solicitud ciudadana de realizarla- y su objetivo es consignar observaciones y propuestas, mas no tiene un carácter vinculante. 
Tanto las consultas ciudadanas impulsadas por el Ejecutivo comola consulta pública ambiental construyen su legitimidad jurídica sobre una equivocación intencional entre forma y fondo: convocan, involucran e interpelan a la ciudadanía sobre temas apremiantes para la misma, pero no menoscaban el poder exclusivo de las instituciones representativas para decidir sobre la imposición de proyectos, programas y políticas públicas.

Estos mecanismos, en los que Rodríguez Garavito (2012) incluye también la consulta a los pueblos indígenas, son ejemplares de un tipo específico de legalidad: la del "paradigma de la gobernanza" que, de acuerdo con Santos (2005), es la matriz jurídica de la globalización neoliberal. Estos mecanismos tienen el efecto de desplazar las acciones reivindicativas de los sujetos colectivos organizados dirigidas a lograr el reconocimiento de sus derechos sustantivos, de tal manera que la acción política de los grupos ciudadanos o los pueblos indígenas se concentra en los asuntos procedimentales/formales -mecanismos administrativos de los procedimientos de consulta, tiempos jurídicos, etcétera-, lo que se define como juridización de las luchas étnicas. Asimismo, la conexión entre el neoliberalismo y las teorías y prácticas de la gobernanza radica en que estas se presentan como espacios "neutros" de negociación y deliberación pero:

soslayan las asimetrías de poder entre los actores involucrados en las deliberaciones - p. ej., las empresas y las comunidades indígenas en los procesos de consulta-y los conflictos redistributivos y culturales que ellas acarrean. Por tanto, los procedimientos y los tipos de participación que defienden dejan intocadas las relaciones de poder y reproducen una visión de la esfera pública como espacio de colaboración despolitizado entre actores genéricos (Rodríguez Garavito, 2012:32).

Entender los procesos de consulta como mecanismos de negociación y no de garantía de derechos es fundamental para ubicar límites y posibilidades de la consulta previa a los pueblos indígenas, proceso en el cual están en juego derechos colectivos fundamentales como los derechos al territorio, la autonomía y la libre determinación.

\section{Consulta previa a los pueblos indígenas y consentimiento}

La legislación internacional y nacional reconoce a los pueblos indígenas derechos específicos que protegen su integridad colectiva en términos culturales, territoriales y políticos, esto es, su autodeterminación - artículo 2 de la Constitución mexicana-. La realización de megaproyectos implica amenazas y afectaciones en general a la libre determinación, y en particular al derecho al territorio de los pueblos indígenas, que "comprende la protección de elementos vinculados a su cosmovisión, identidad cultural, vida espiritual, formas propias de subsistencia y en suma, su supervivencia física y cultural como pueblos diferenciados" (CIDH, 2015).

La principal herramienta jurídica utilizada internacionalmente en la defensa de los derechos territoriales es el Convenio 169 sobre Pueblos Indígenas y Tribales de la Organización Internacional del Trabajo (OIT, 1989), ratificado por México en 1989 y que tiene actualmente carácter vinculante. Este documento es el marco de referencia sobre la consulta, mecanismo necesario para garantizar el respeto a los derechos colectivos a la libre determinación y al territorio.

El artículo 6 del Convenio 169 establece la obligación de los gobiernos a "consultar a los pueblos interesados, mediante procedimientos apropiados y en particular a través de sus instituciones representativas", esto es, sus propias autoridades y sistemas de organización, toma de decisiones y gobierno, "cada vez que se prevean medidas legislativas o administrativas" como concesiones mineras o de agua, permisos de electricidad o para la construcción, autorizaciones ambientales "susceptibles de afectarles directamente" y, con ello, afectar el desarrollo de la vida misma de los pueblos. Se establece la necesidad de la consulta al realizar planes nacionales para el proceso 
de desarrollo del país (OIT, 1989: art. 7) y antes de emprender o autorizar un programa de explotación de recursos dentro de territorios indígenas (OIT, 1989: art. 25).

El objetivo del proceso de consulta será “llegar a un acuerdo o lograr el consentimiento acerca de las medidas propuestas" (OIT, 1989: art. 6), punto en el cual se ubica el meollo de la disputa entre los pueblos indígenas organizados y los actores - Estado y empresas- que impulsan los proyectos extractivos y de infraestructura (Murcia, 2019). En este aspecto, la cuestión principal no radica en la mera realización de la consulta —en su carácter procedimental-, sino en reconocer la posibilidad de que no se llegue a un acuerdo y en que el consentimiento se pueda lograr - o no- y entonces que el resultado de la consulta, aun cuando resulte negativo, sea vinculante.

Sin embargo, esta resulta una condición muy incómoda para instituciones y poderes de facto, que acostumbran limitarse a realizar procesos de consulta y seguir en la implementación de proyectos y programas sin tomar en consideración el consentimiento o la negativa resultado de tales procesos (López, 2013; Espinoza, 2019). Al respecto, la Corte Interamericana de Derechos Humanos, en su jurisprudencia, se ha referido al "deber de acomodo", que obliga a los Estados a "ajustar o incluso cancelar el plan o proyecto con base en los resultados de la consulta con los pueblos indígenas, o, en defecto de tal acomodo, el de proporcionar motivos objetivos y razonables para no haberlo hecho" (CIDH, 2009: párr. 324). Aquellas decisiones que no expresen las razones relativas a la falta de acomodo podrán ser consideradas contrarias a las garantías del debido proceso y violatorias de los derechos humanos. Para enfrentar el laxismo de los Estados en la realización de los procesos consultivos, la misma Corte ha definido circunstancias específicas en las que la obtención del consentimiento "previo, libre e informado" es obligatoria e insoslayable: cuando se trate de "planes de desarrollo o inversión a gran escala que tendrían un mayor impacto dentro del territorio" de los pueblos indígenas (Corte IDH, 2007): considerando también los impactos acumulados de proyectos menores; en el caso de almacenamiento o eliminación de residuos peligrosos en su territorio (CIDH, 2009: párr. 334); cuando se quieran realizar actividades militares, y cuando los pueblos estén amenazados de desplazamiento, de acuerdo con el artículo 16 del Convenio 169 de la OIT (1989).

La apelación al derecho a la consulta por parte de los pueblos indígenas y la impugnación de megaproyectos de diverso tipo con el argumento de la violación a este derecho se ha vuelto muy frecuente en todo el continente latinoamericano. En México, fue pionera la experiencia del Consejo de los Pueblos Nahuas del Alto Balsas, en el estado de Guerrero, en contra del proyecto hidroeléctrico (presa) San Juan Tetelcingo, en 1990, apenas unos meses después de que México ratificara el Convenio 169 de la OIT. La del Alto Balsas fue la primera lucha en reivindicación de la identidad indígena, y no el derecho agrario, para la defensa territorial; y fue también la primera experiencia organizativa que logró la cancelación del proyecto y detener el desplazamiento forzado de la población nahua guerrerense.

En años sucesivos, varias leyes federales han incluido de manera específica la realización de la consulta indígena: la Ley de Hidrocarburos, de la Industria Eléctrica, de la Energía Geotérmica, de Planeación y de Desarrollo Forestal Sustentable. ${ }^{3}$

Los actores principales del proceso de consulta son los pueblos indígenas y sus instancias representativas - sujetos de la consulta-, que los pueblos tienen el derecho de escoger de manera autónoma; y las autoridades del Estado, encargadas de realizar la consulta. Según la jurisprudencia producida por la CIDH y la Declaración de las Naciones Unidas sobre los Derechos de los Pueblos Indígenas (art. 10), cada proceso de consulta debe ser "previo" - llevarse a cabo antes de realizar cualquier medida legislativa, acto administrativo o autorización-, "libre" —en condiciones de seguridad y libre participación, sin que exista coerción o intimidación — , "informado" — que los pueblos tengan acceso a toda la información relevante para tomar decisiones - y "culturalmente apropiado" -debe respetar las autoridades representativas 
de los pueblos, además de que debe realizarse con procedimientos que correspondan a los sistemas sociales y culturales propios, tanto en el diseño de la información como en su difusión y en el propio proceso consultivo-.

A ellos se suma el principio "de buena fe" (OIT, 1989: art. 6), lo que significa que quien realiza la consulta no debe tener intereses específicos que lleguen a incidir en el resultado y que debe realizarse sin que se pretenda engañar o brindar información sesgada o parcial en el tema a consultar. Según diversos estudios en los que se proponen análisis comparativos de casos de consulta en México (Leyva et al., 2018; Gómez, Arcos y Villagómez, 2017; Gutiérrez y Del Pozo, 2019) este principio es sistemáticamente violado, pues las autoridades responsables son las mismas que impulsan los proyectos de inversión en complicidad con las empresas beneficiadas, lo que las convierte en juez y parte de los proyectos, "prueba de ello es el hecho de que las propias autoridades federales han sido las que impugnaron las sentencias favorables que los juzgadores otorgaron a las comunidades indígenas" (Gómez, Arcos y Villagómez, 2017:5). A la misma conclusión llega la Comisión Interamericana de los Derechos Humanos, que detecta la violación del principio de buena fe en todo el continente y denuncia "prácticas de desarticulación social y amenazas a líderes y lideresas indígenas con el objetivo de debilitar la representatividad de los pueblos" (CIDH, 2015:108).

Los casos analizados en los estudios citados evidencian que las instituciones se aproximaron al proceso de consulta como un mero trámite para reafirmar proyectos ya aprobados y negociados con grupos de interés económico, o incluso ya en marcha —violando su carácter "previo"-, simulando y manipulando la participación ciudadana incluso por medio de actos intimidatorios o con el uso de la violencia —violando su carácter de "libre" — (López, 2013:86). ${ }^{4}$

Entre los principios fundamentales que debería cumplir un proceso de consulta, señalados por Cruz Rueda (2008), destaca la difusión de información clara y objetiva sobre los impactos de los proyectos a consultar en términos de afectaciones y beneficios posibles, así como de transformación en su entorno ambiental y social, lo cual corresponde al carácter de "informada" de la consulta. Por el contrario, la desinformación ha sido históricamente una constante en los megaproyectos de desarrollo impulsados desde los gobiernos. Esto representa el primer elemento que genera la oposición tajante a dichos proyectos, pues son percibidos como una imposición externa que no abona a la construcción de una ciudadanía participativa, sino que más bien vulnera los derechos individuales y colectivos de la población, no solamente indígena sino también rural y urbana.

Otra constante es la acusación de ignorancia y desinformación que se dirige hacia los pueblos indígenas y quienes apoyan sus luchas, razón única de la cual dependería, en la narrativa del poder, su oposición a los megaproyectos. Al respecto, es evidente que es obligación de las instituciones y autoridades competentes vehicular hacia la población toda la información disponible y necesaria para la comprensión de riesgos y oportunidades del proyecto o medida. La falta de información, al contrario, es utilizada con frecuencia por los mismos funcionarios como un elemento para descalificar y culpabilizar a los mismos que la solicitan y que carecen de ella no por voluntad propia, sino por la opacidad de los planes de gobierno. La información proporcionada en la etapa de consulta debe ser veraz y objetiva, lingüística y culturalmente adecuada, y sobre todo tiene que ser accesible para los principales interesados, es decir, para quienes habitan en los territorios y que resultan ser casi siempre el último eslabón en el proceso social y político de gestación de las grandes obras. Sin embargo, considero que la obligación institucional de informar sobre proyectos y programas no se debe reducir al proceso de consulta, sino que debe ser una prioridad institucional en todo momento, de tal forma que los proyectos ejecutivos y los estudios de impacto de estas grandes obras deberían ser conocidos antes de la consulta, e incluso previamente al anuncio de planes y licitaciones para la construcción. 


\section{Libre determinación, territorio y consulta}

Para ubicar correctamente el tema de este texto es necesario remarcar que el derecho a la consulta y al consentimiento es un derecho adjetivo o procedimental para la garantía de derechos sustantivos hacia los cuales se enfoca la reivindicación de los pueblos indígenas. Estos son el derecho a la libre determinación y el derecho al territorio en su integridad. El derecho a la consulta es un medio, no un fin en sí mismo, y así deben entenderse las apelaciones a su violación por parte de pueblos y comunidades indígenas; se trata del uso "estratégico" de un recurso legal, de tal manera que apelar al derecho a la consulta o a su violación se ha demostrado una herramienta eficaz cuando la concesión está otorgada pero la obra aún no ha iniciado. ${ }^{5}$

El derecho al territorio implica, primordialmente, "el derecho de propiedad y de posesión sobre las tierras que [los pueblos indígenas] tradicionalmente ocupan" (OIT, 1989: art. 14.1).

El término territorio tiene una fuerte caracterización jurídica por su significación en cuanto derecho; sin embargo, la trascendencia misma del derecho al territorio reside en la multiplicidad de significaciones que este tiene. Por "territorio" se entiende una entidad espacial conformada por la cultura y por la historia de los grupos sociales y las identidades colectivas que en él radican; incluye los aspectos culturales y simbólicos, las potencialidades productivas y reproductivas, las implicaciones políticas y las relaciones de poder. Desde la disciplina antropológica se ha estudiado con amplitud la relación mutuamente constitutiva entre territorio y cultura (Giménez, 2000) y el "uso de los recursos naturales según patrones culturales" en el territorio biocultural (Boege, 2008). La significación cultural del territorio se hace evidente en la organización de las actividades productivas tradicionales o ciclos agrícolas, ordenados por momentos rituales y festivos en los que se reafirma el vínculo estrecho entre las personas y el territorio donde viven, invocando o agradeciendo buenas cosechas y una relación positiva con los elementos naturales de los que depende la misma sobrevivencia humana. La dimensión cultural determina modos y medios de la apropiación productiva de la tierra, ya sea en las más tradicionales agriculturas de subsistencia como en los cultivos comerciales, siempre y cuando se trate de actividades realizadas por los mismos campesinos y miembros de la comunidad de forma autónoma - por el contrario, los monocultivos y las agroindustrias operan en el sentido de la destrucción de significados territoriales-.

Considero de gran importancia enfatizar la dimensión identitaria, cultural y simbólica del territorio, pues de acuerdo con tal perspectiva las afectaciones ocasionadas por megaproyectos pueden tener impactos mucho más extensos y profundos de aquellos evidenciados en los mecanismos de evaluación como la "manifestación de impacto ambiental" o la "evaluación de impacto social". En tal sentido, el Convenio 169 de la OIT conmina a los gobiernos a "respetar la importancia especial que para las culturas y valores espirituales de los pueblos interesados reviste su relación con las tierras o territorios, que ocupan o utilizan de alguna otra manera, y en particular los aspectos colectivos de esa relación" (OIT, 1989: art. 13.1).

El derecho al territorio es inseparable del derecho a la libre determinación, que es la base de la deliberación sobre el uso y aprovechamiento de los bienes comunes naturales. La libre determinación, cuyo ejercicio supone la expresión de la voluntad colectiva, está reconocida en el artículo 2 de la Constitución mexicana. Su formulación más acabada se encuentra en el texto seminal de las luchas indígenas contemporáneas en México, los Acuerdos de San Andrés, en el cual el Estado mexicano se comprometió a respetar "las capacidades de los pueblos y comunidades indígenas para determinar sus propios desarrollos" (Acuerdos de San Andrés, 1996: doc. 1).

Los derechos al territorio y a la libre determinación son derechos sustantivos; estos, según la tesis jurisprudencial emitida por la Suprema Corte de Justicia de la Nación, son aquellos "que se identifican con los bienes de la vida" (SCJN, 2017) y demandan "respeto irrestricto". Por lo anterior, en muchos megaproyectos ubicados en territorios cuya propiedad, posesión o uso histórico es claramente atribuida a 
pueblos indígenas, la sola existencia del proyecto en sí ya es una violación a estos derechos sustantivos. Esto se debe a que la proyección de una intervención por parte de sujetos externos al territorio y al pueblo indígena - como instituciones o empresas - implica el supuesto de que las necesidades de la población asentada en la región a intervenir no son dignas de interés o en todo caso no son prioritarias; $y$ por ende se planearon de manera heterodirecta proyectos que, en un momento posterior, eventualmente serán sometidos a procesos de consulta para recabar opiniones y sugerencias. Si se otorgara prioridad a los derechos sustantivos al territorio y a la libre determinación, se trabajaría en la realización conjunta entre población, instituciones y empresas de planes de vida o agendas de desarrollo colaborativas, como paso necesario para la planeación de proyectos que respondan a las necesidades de quienes habitan cada territorio y de acuerdo con sus especificidades culturales.

El creciente apremio de instituciones y empresas por garantizar la ejecución de consultas a los pueblos indígenas genera una apariencia de respeto a los derechos colectivos, pero sin acatar o fundamentar políticas y proyectos en los derechos sustantivos al territorio y a la libre determinación. En el caso de la consulta, su particularidad sería distinta si se acatara el carácter sustantivo del derecho al territorio.

La discusión alrededor de algunos casos, en el apartado que sigue, servirá de fundamento para profundizar en la argumentación que sostiene la inconsistencia de la consulta como derecho y su inoperancia como procedimiento. Magdalena Gómez afirma al respecto:

[...] es distinto que se haga una propuesta a quien tiene un derecho reconocido, en este caso los pueblos indígenas y ellos decidan si la aceptan o no. No se trata de un derecho de veto, es un derecho a secas, ni más ni menos. Vetar significaría detener una decisión ya tomada por alguien distinto a quien tiene la titularidad del derecho, así sea el Estado o la trasnacional que obtuvo una concesión (Gómez, 2017:151).
El problema de fondo reside en que las decisiones institucionales violan abiertamente los derechos sustantivos al territorio y a la libre determinación, por lo cual los procesos de consulta se vuelven mecanismos de intervención social para la obtención de consensos sobre proyectos de inversión o intervención que no responden a los intereses ni a las necesidades de la ciudadanía ni de la nación.

\section{La consulta indígena en México en la Cuarta Transformación. Escenarios de incertidumbre}

La indiferencia hacia los derechos fundamentales de los pueblosindígenas y la manipulación de los instrumentos legales para su garantía están entre las preocupaciones expresadas por Victoria Tauli-Corpuz, relatora especial de las Naciones Unidas sobre los derechos de los pueblos indígenas, en una nota técnica enviada al gobierno de México el 5 de marzo de 2019. En el documento subraya que los procesos de consulta ciudadana, caballo de batalla de la Cuarta Transformación, " "no garantizan las salvaguardas de los derechos de los pueblos indígenas" (Tauli-Corpuz, 2019:1). Al respecto, la relatora recuerda a las autoridades mexicanas la especificidad del proceso de consulta a los pueblos indígenas, ya que:

[...] son necesarios procedimientos especiales y diferenciados de consultas cuando se afectan los derechos de los pueblos indígenas que derivan del carácter distinto de los modelos e historias culturales de los pueblos indígenas, y porque los procesos democráticos y representativos corrientes no suelen bastar para atender a las preocupaciones particulares de los pueblos indígenas, que por lo general están marginados en la esfera política [...] (Tauli-Corpuz, 2019:6).

Analizar y sacar conclusiones de procesos en curso en los cuales estamos involucrados es un ejercicio peligroso que puede llevar a consideraciones parcialese incorrectas. Sin embargo, el ejercicio de reflexión crítica sobre la cotidianidad vivida es el paso prístino para la investigación social, por lo cual a continuación propongo 
algunas ideas sobre la representación de escenarios sociales actuales y en fase de rápida transformación. Anoto con ellas algunos panoramas críticos y puntos de inflexión para futuras investigaciones.

\section{Opinar en contextos de violencia}

El Frente de Pueblos en Defensa de la Tierra y el Agua de Morelos, Puebla y Tlaxcala (FPDTAMPT) desde 2012 se opone a la construcción del Proyecto Integral Morelos. Este megaproyecto incluye: dos centrales termoeléctricas en la comunidad de Huexca; un gasoducto de 170 kilómetros que transportaría diariamente nueve mil millones de litros de gas natural desde Puebla hacia las termoeléctricas, pasando por las faldas del volcán Popocatépetl y a través de más de sesenta comunidades campesinas de los estados de Tlaxcala, Puebla y Morelos; una línea eléctrica de veinte kilómetros desde Huexca a la subestación Yautepec, y un acueducto que trasladaría cincuenta millones de litros de agua diarios desde el río Cuautla a las termoeléctricas (Centro Fray Julián Garcés, 2019; CFE, 2011). El impacto ambiental, productivo, social y en términos de seguridad de este megaproyecto, que trasladaría diariamente una enorme cantidad de gas natural por las faldas de un volcán activo, es incalculable, ${ }^{7}$ al igual que la contaminación de las aguas residuales al salir de la termoeléctrica, pero también es enorme la codicia de Elecnor, Enagas, Abengoa y Bonatti, empresas trasnacionales a las que fue licitada la construcción de la obra que, desde 2016, está suspendida por el plantón permanente que la organización popular mantiene en Huexca. Pero mientras la obra está parada, las empresas siguen cobrando la cuota por un servicio que no ofrecen a la Comisión Federal de Electricidad, dependencia estatal. Por tal razón, el Ejecutivo actual decidió destrabar el asunto y el presidente de la República, en un acto público en Cuautla el 10 de febrero 2019, acusó a los pueblos que defienden su territorio y su vida de ser radicales de izquierda, iguales a los ultraconservadores, sobornados por las empresas extranjeras para defraudar al Estado mexicano (Presidencia de la República, 2019). La cuestión se resolvió con una nueva consulta ciudadana, definida como "ejercicio participativo", que se realizó trece días después, el 23 y 24 de febrero de 2019; de esas consultas que la misma secretaria de Gobernación calificó como carentes de legalidad ("Sánchez Cordero contradice a AMLO...", 2019). De hecho, esa tal vez fue la consulta más ilegítima, ya que en tres estados - Puebla, Tlaxcala y Morelos - votaron apenas 55000 personas, de las cuales el 59 \% expresó su consentimiento (Herrera, 2019; Núñez, 2019).

Antes de su realización, la "consulta" ya se había manchado con la sangre de un reconocido activista y comunicador morelense. En la madrugada del 20 de febrero de 2018, apenas tres días antes de la celebración de la "consulta", pocas horas después de participar en un foro con presencia de autoridades federales donde denunció públicamente las irregularidades de la termoeléctrica, Samir Flores, de 36 años de edad, fue acribillado a balazos fuera de su casa, en la comunidad de Amilcingo, Morelos. Su asesinato tiene la misma marca de los cientos, miles de crímenes contra defensores de los derechos y de los territorios y contra luchadores sociales que tristemente son el pan de cada día en un país donde la impunidad y la violencia son práctica institucional. Pero no basta: su lucha es descalificada también después de su muerte, en un proceso recurrente en el que las autoridades invisibilizan el móvil político de los crímenes y los fincan como delitos de otra índole. En el caso de Samir Flores, la Procuraduría de Justicia del Estado afirmó en sus primeras declaraciones que el asesinato debía atribuirse al crimen organizado, interpretación que ahondó la crispación entre familia, compañeros y demás opositores al proyecto.

El "ejercicio participativo", como es definido en los folletos informativos entregados a quienes acudieron a las casillas, contrasta con la citada nota técnica de la relatora de las Naciones Unidas sobre los pueblos indígenas (Tauli-Corpuz, 2019), pues la población a la cual se aplicó es en su mayoría indígena y pertenece al pueblo nahua. Incluso, el municipio de Hueyapan obtuvo recientemente el reconocimiento para operar según usos y costumbres. En este caso, debería haberse implementado la consulta indígena 
según los mecanismos reconocidos por la legislación internacional y, por tal razón, pocos meses después el Tribunal Colegiado en Materia Administrativa ordenó a los jueces aceptar el amparo interpuesto por ocho comunidades indígenas en contra de la "consulta" realizada (Llaven, 2019). El derecho a la consulta, instrumentado institucionalmente, cuestionado o reivindicado estratégicamente, sigue estando en el centro del nudo gordiano, y el Proyecto Integral Morelos sigue detenido.

\section{Cuestión de temporalidades. $1^{\circ}$ Los tiempos de la consulta $y$ los tiempos del mercado}

"Hoy, 26 de marzo de 2019, la Secretaría de Hacienda y Crédito Público difunde la convocatoria para la consulta a las comunidades y pueblos indígenas sobre el Proyecto de Desarrollo del Istmo de Tehuantepec...", declama el locutor del noticiero mañanero.

“iAh! iYa viene!", pienso al escuchar la noticia. "Y apenas ayer estaba en el foro con representantes de pueblos y organizaciones de Oaxaca, que demandan un proceso transparente y respetuoso de los estándares internacionales para la realización de este tan delicado proceso de consulta... iOjalá esta vez lo hagan bien!", me digo, pero al mismo tiempo el balde de agua fría llega con la continuación de la nota radiofónica: “... que se realizará este sábado 30 y domingo 31 de marzo a través de siete asambleas regionales consultivas. En cada asamblea se desarrollarán las etapas informativa, deliberativa, de consulta y toma de acuerdos..."

La Cuarta Transformación muestra una elevadísima capacidad de apropiación y transformación de los mecanismos legales y de gobernanza para amoldar la institucionalidad existente a la agenda del nuevo Ejecutivo, de tal manera que se pregona la realización de la consulta a los pueblos indígenas con fundamento en la legislación nacional e internacional, pero se pervierten desde adentro las formas y mecanismos para su implementación.

El llamado Proyecto de Desarrollo del Istmo de Tehuantepec (o Corredor Transístmico) interesa a los estados de Oaxaca y Veracruz, y a los territorios de los pueblos indígenas chontales, huaves, mixes, zapotecas, zoques, nahuas y popolucas. Meollo del megaproyecto es el Corredor Multimodal Interoceánico, cuyo objetivo es conectar el océano Pacífico y el Atlántico para facilitar y acelerar el tránsito de mercancías, plan que han perseguido todos los gobiernos desde $1980 \mathrm{sin}$ lograr llevar a cabo la obra faraónica (Rodríguez, 2000 y 2003). Ahora se prevé la rehabilitación y modernización del ferrocarril del Istmo de Tehuantepec, la ampliación de los puertos de Coatzacoalcos (Atlántico) y Salina Cruz (Pacífico), y la construcción de nuevos ejes carreteros y de un gaseoducto para abastecer a las empresas que se asentarían en las dos zonas portuarias, recién declaradas “zonas económicas especiales". Y para 2021, al terminar la obra, todo el Istmo se declararía zona libre de impuestos. ${ }^{8}$

La oposición popular a la obra se ha manifestado cada vez que el gobierno en turno proponía su versión del Corredor, llámese Plan Alfa Omega (gobierno de De la Madrid), Megaproyecto del Istmo (gobierno de Zedillo), el más amplio Plan Puebla Panamá (gobierno de Vicente Fox) o Plan Istmo Puerta de América (gobierno de Peña Nieto) (Torres, 2017). Es bien sabido que quienes habitan en las regiones rurales del Istmo condenan esta intervención y reordenamiento territorial mercantil. En este caso, posiblemente, la consulta a los pueblos indígenas hubiera sido incluso innecesaria, y es por eso que su realización tan discrecional expone un carácter de medida de legitimación, más que de democratización de las políticas públicas.

La "consulta" realizada el 30 y 31 de marzo de 2019, que tuvo como resultado que "las voces y los planteamientos de los pueblos fueron escuchados", según un comunicado oficial (INPI, 2019a), presentó varias irregularidades. En primer lugar hace evidente la manipulación de los tiempos necesarios para la realización de la consulta porque el anuncio público se difundió apenas tres días antes de su inicio, con lo cual no se permitió a la población interesada organizarse para reflexionar y actuar al respecto. En segundo lugar, el protocolo ${ }^{9}$ preveía la realización en un solo día de las etapas informativa, deliberativa, y de consulta y acuerdos, ${ }^{10}$ lo cual abiertamente ignora 
el respeto a los tiempos, usos, costumbres y formas de toma de decisión de las comunidades. ¿Cómo puede ser ponderada una decisión colectiva sobre transformaciones irreversibles al territorio, cuando se concedió el lapso de unas horas para que las personas recibieran la información - no traducida a sus idiomas-, la asimilaran, la discutieran, decidieran y votaran sobre su futuro? Lo acontecido en el Istmo es exactamente lo contrario a lo que la relatora de la ONU recomendaba menos de un mes antes al gobierno mexicano:

Los procesos de consulta deben proporcionar el tiempo y los espacios necesarios para que los pueblos indígenas puedan tener pleno conocimiento sobre el alcance y los impactos de la medida propuesta antes de su aprobación y para que puedan incidir e influir en la toma de decisiones que repercuten en sus derechos, así como para plantear sus propias propuestas (TauliCorpuz, 2019:6)

Por otra parte, la consulta del Istmo evita asumir la obligatoriedad del consentimiento, ya que plantea como objetivos: "Recibir opiniones, propuestas, sugerencias y planteamientos de los pueblos y comunidades indígenas con relación al contenido del Programa de Desarrollo del Istmo de Tehuantepec" y "establecer acuerdos" con los mismos pueblos y comunidades. Asimismo, según la CNDH (2019), "afecta a su sistema normativo interno al implantar una figura de Asamblea Regional Consultiva" que no existiera ni puede representar una autoridad "representativa de los pueblos" según mandata el Convenio 169 (OIT, 1989). La memoria corre unas décadas atrás y encuentra en estas asambleas un rancio resabio de los Consejos Supremos Indígenas, instancias falsamente representativas creadas por las instituciones indigenistas en los años setenta para fungir como interlocutores orgánicos con el gobierno. Remarcando esta ilegitimidad, las comunidades ikoots, binnizá y zoques rechazaron abiertamente la realización de la consulta y desconocieron la instalación de la Asamblea Regional Consultiva.

\section{Cuestión de temporalidades $2^{\circ}$. Consulta previa, ipero previa a qué?}

El megaproyecto denominado Tren Maya prevé la adecuación y construcción de una línea férrea de 1460 kilómetros a través de los estados de Chiapas, Tabasco, Campeche, Yucatán y Quintana Roo, y la operación de un tren alimentado con diesel para transporte de carga y pasajeros. Este proyecto, más allá del servicio de transporte, contempla "reordenar el territorio" a partir de la creación de numerosos "polos de desarrollo", esto es, de nuevos centros de población y zonas agroindustriales y de la ampliación de los ya existentes. Al integrar los destinos turísticos con aeropuertos, estaciones ferroviarias y puertos proyecta el acceso al patrimonio cultural de la región. ${ }^{11}$

En los meses sucesivos a la elección de López Obrador para la Presidencia de la República se dieron a conocer a grandes rasgos los datos del megaproyecto, impulsado con fuerza desde el Ejecutivo y que fue objeto de una Consulta Nacional - procedimiento sin ningún fundamento legal- los días 24 y 25 de noviembre de 2018, junto con un paquete de diez programas prioritarios. De los 946081 participantes, el 89.9 \% votó a favor del proyecto. De todos modos, antes de dicha "consulta", el presidente se adelantó a afirmar que la construcción del Tren Maya arrancaría el 16 de diciembre de 2018, dio a conocer la ruta y los tramos, y anunció la licitación del proyecto. Más de un año después, en enero de 2020, aún no se conoce el plan maestro ni los proyectos ejecutivos y no se han dado a conocer las evaluaciones de impacto ambiental y social.

En ausencia de información básica y exhaustiva sobre los fundamentos y los alcances del megaproyecto de infraestructura, turístico y de ordenamiento territorial, entre diciembre de 2018 y enero de 2019 el Ejecutivo y distintas dependencias del gobierno han llevado a cabo un sinnúmero de actos de autoridad que, en su conjunto, constituyen graves y reiteradas violaciones al carácter previo de la consulta. El primer acto consistió en el Ritual de los Pueblos Originarios a la Madre Tierra para Anuencia del Tren Maya, encabezado por el presidente de la República en Palenque, Chiapas, en el contexto 
del cual el mandatario colocó la "primera piedra" de la obra. El evento político tuvo la abierta intención de legitimar el proyecto incursionando en la dimensión ritual, que tiene particular relevancia en las culturas indígenas; organizaciones indígenas denunciaron el uso político e instrumental de la práctica ceremonial y de los símbolos maya por parte de funcionarios ajenos a los mismos pueblos.

Cabe señalar que elusoestetizante de trajes y adornos ceremoniales indígenas, así como la incorporación de un discurso "indigenista" de respeto paternal a los derechos de los pueblos, son una marca del actual Ejecutivo; en este contexto se inscribe el aparente respeto al derecho a la consulta del que se hace alarde, aunque en los hechos tal derecho sea repetidamente violado.

El carácter previo de la consulta fue trastocado por las múltiples licitaciones emitidas, los 158 contratos sellados -en su mayoría para estudios técnicos y de factibilidad-y la ingente cantidad de fondos públicos erogados a los titulares de estos —863 914791 pesos mexicanos - antes del 15 de noviembre de 2019. ${ }^{12}$ Aclaramos que "previa" no significa antes de que inicie materialmente la obra, sino que "desde las primeras etapas de la elaboración y planificación de la medida propuesta" (Corte IDH, 2012:5). Antes de todo, primero que nada, hay que consultar a la población indígena interesada.

El 15 de noviembre de 2019 se dio a conocer, después de casi un año de arranque del proyecto, la convocatoria para el proceso de consulta a los pueblos indígenas "que se encuentran en el área de influencia del Proyecto, respecto de su participación en la implementación de dicho proyecto, así como en la distribución justa y equitativa de los beneficios" (INPI, 2019b). Los tiempos del proceso, aunque más extendidos que en el caso del Corredor Transístmico, resultaron nuevamente muy apretados: quince días después de la difusión de la convocatoria se llevaron a cabo las asambleas informativas, y después de otros quince días, el 15 de diciembre de 2019, las asambleas consultivas.

Elproceso, como era de esperarse, dio como resultado la aprobación del Tren Maya, con un porcentaje favorable del $92.3 \%$ del total de los 100940 votantes; en términos absolutos, quienes votaron por el sí corresponden apenas al $2.78 \%$ de los 3344522 personas que habitan en los 84 municipios donde se realizó la consulta. ${ }^{13}$ Esto se debe a las propias características del proceso consultivo, que está dirigido a autoridades e instituciones representativas de los pueblos indígenas y no a la población en general; sin embargo, fuentes entrevistadas refieren que no fueron invitadas, ni fueron reconocidas como tales las autoridades tradicionales y las instancias de representación colectiva indígena - como el Consejo Regional Indígena Maya de Bacalary el Consejo Regional Indígena y Popular de Xpujil—. Se reconocieron como autoridades indígenas solo aquellas que están insertas en la institucionalidad estatal, esto es, las autoridades agrarias -Comisariados Ejidales y de Bienes Comunales-y administrativas - agentes, comisarios o delegados municipales-(CCMSS, 2019). Este punto es de gran relevancia porque implica un desconocimiento profundo de los derechos sustantivos a la libre determinación y la autonomía, que incluyen la facultad para los pueblos indígenas de elegir sus propias formas de gobierno.

Otro elemento de gran relevancia en este recién concluido proceso de consulta, señalado por la Oficina en México del Alto Comisionado de las Naciones Unidas para los Derechos Humanos, fue que "las personas de las comunidades expresaban su conformidad con el proyecto como un medio para recibir atención a necesidades básicas como agua, salud, educación, trabajo, vivienda, medio ambiente sano y cultura, lógica que afecta el carácter libre de la consulta" (ONU-DH, 2019); incluso, asistentes entrevistados afirman que en concomitancia con las asambleas se instalaron mesas de atención de la Secretaría de Bienestar para regularizar el acceso a programas sociales de quien lo requiriera. ${ }^{14}$ Esto enfatiza la grave carencia en lo que corresponde a los servicios básicos para la población indígena, lo cual redunda en la violación de sus derechos fundamentales; sin embargo, la dinámica resultó en una suerte de intercambio político entre la atención a los derechos ciudadanos por parte de las instituciones, a cambio de la anuencia al megaproyecto y la intervención territorial. 


\section{Conclusiones}

El análisis de las características de los distintos tipos y procesos de consulta realizados en México en tiempos recientes, así como la discusión de casos emblemáticos de consulta en regiones indígenas impulsados en el año 2019, permitió enfatizar, a partir de elementos concretos y específicos, los ya mencionados problemas y limitaciones consustanciales al mismo procedimiento consultivo.

El resultado de los procesos de consulta indígena, casi siempre favorable al megaproyecto, reside en que no se trata de una votación individual secreta, sino de un complejo proceso de construcción de consenso en el cual las autoridades representativas de los pueblos expresan su opinión — no su voto- - que debería reflejar la opinión consensuada de toda la comunidad, pueblo u organización. El mecanismo se presta a un sinnúmero de manipulaciones, desde fomentar grupos con posición favorable al proyecto y propiciar su enfrentamiento con los opositores, hasta la simple compra de voluntades de los representantes o el intercambio de consenso con el ofrecimiento de acceso a programas sociales — politización de la asistencia social- Es sumamente difícil que un proceso de consulta logre estar realmente libre de presiones, mientras es muy común que se vea influenciado por los grupos de interés más poderosos, comúnmente afines a empresas y gobiernos.

Por otro lado la creciente instrumentación de la consulta por parte de las instituciones, justo como mero "procedimiento" cuyo resultado previsible la transforma en un requisito formal para avanzar en el desarrollo de los megaproyectos, limita ampliamente la posibilidad de entender y reivindicar la consulta como derecho. Frente a la apropiación institucional del ejercicio de la consulta, incluso la práctica de reivindicar estratégicamente la falta de respeto a tal derecho - que permitió a distintos pueblos indígenas ganar controversias jurídicas - aparece como inconsistente y de dudosa utilidad en el futuro.

Se perfila por lo tanto la necesidad de replantear la perspectiva jurídica y de los derechos en relación con la defensa de los territorios indígenas y campesinos.
Al respecto, Espinoza afirma que "la consulta no es el único medio a disposición de las comunidades para la defensa jurídica de la propiedad social o la reivindicación del territorio. No es el recurso idóneo ni el más efectivo para tutelar los derechos individuales y colectivos de las comunidades. Tampoco es el instrumento absoluto para la expresión de la voluntad colectiva" (Espinoza, 2019:90). Para esto, el jurista sugiere la contundencia de "declaraciones unilaterales de la voluntad", que definen una postura colectiva frente al megaproyecto antes o independientemente de la realización de la consulta. Ejemplo de tal herramienta son las actas de asamblea en las que, en comunidades de Chiapas, Morelos, Oaxaca y Guerrero, se ha expresado el rechazo a las actividades extractivas al declararse "territorios libres de minería" (Gasparello, 2016). La inscripción de estas actas en el Registro Agrario Nacional las convierte en documentos públicos y oficiales a nivel federal, por lo cual la explotación minera no podría ser sometida a consulta. Esta práctica se fundamenta justo en el ejercicio de la autonomía y la libre determinación, pues los sujetos colectivos que habitan en el territorio, en lugar de ser consultados sobre algo que no han propuesto ni solicitado, recuperan su propia agencia en la expresión de su voluntad afirmativa. En esto se encuentra implícita también una reivindicación extensa del territorio como medio de vida, conjunto simbólico e identitario, lugar de la memoria y del futuro colectivo, reconociendo que la diversidad de las posibles afectaciones no podrá ser reparada con "medidas de mitigación" ni con la participación o redistribución de los posibles beneficios.

Como conclusión del análisis y de la argumentación propuesta, regreso sobre la necesidad de posicionar los derechos sustantivos al territorio y a la libre determinación como eje de las reivindicaciones políticas y jurídicas.

En el caso de la implementación de un megaproyecto, los derechos a la libre determinación y al territorio permiten la articulación de acciones afirmativas con un alcance mucho más profundo que la perspectiva "defensiva" que permite el acotado derecho a la consulta; asimismo, se trata de derechos que reflejan 
prácticas reales y vigentes entre los pueblos indígenas, al conjuntar en un enfoque integral varias dimensiones de la vida social.

La demanda de reconocimiento de los derechos a la autonomía y la libre determinación, que en México fue bandera del movimiento indígena desde los años noventa y aún espera ser cumplida, adquiere nueva contundencia en la coyuntura contemporánea de acelerado despojo territorial y cultural.

\section{Notas}

1 Las convocatorias y los resultados están disponibles en: https://www.mexicodecide.com.mx/NAIM/index. html y en https://lopezobrador.org.mx/temas/consultanacional/

2 Ver: "Tren Maya iría a consulta..." (2019).

3 Sobre las contradicciones específicas en las que se ha incurrido en la aplicación de este último tipo de consulta véase González (2016).

${ }^{4}$ Los casos de consultas al pueblo zapoteco de Juchitán (Oaxaca) sobre la concesión de su territorio para un proyecto eólico y al pueblo yaqui sobre la explotación del río Yaqui para el acueducto Independencia son ejemplos tajantes de violaciones de estos dos tipos.

${ }^{5}$ Ejemplo son los casos del pueblo wixárica en contra de la explotación minera en el sitio sagrado de Wirikuta, y del pueblo mé phaa en contra de la misma actividad en la Montaña de Guerrero (Gasparello, 2016).

${ }^{6}$ Definición que se ha dado a sí mismo el actual gobierno de México (2018-2024).

7 Para más información ver: "Proposición con punto de acuerdo..." (2013) y “Geopolítica de los megaproyectos..." $(\mathrm{s} / \mathrm{f})$.

8 Ver: Proyectos México Oportunidades de Inversión (2019).

9 Elaborado por el Instituto Nacional de los Pueblos Indígenas y la Secretaría de Hacienda y Crédito Público.

${ }^{10}$ Protocolo y convocatoria disponibles en: https://www. gob.mx/consultaistmo (consultado el 5 de abril de 2019).

${ }^{11}$ Ver la página oficial del proyecto disponible en: https:// www.tren-maya.mx/ (consultado el 2 de abril 2019).
12 Ver: https://compranet.hacienda.gob.mx/web/login. html (consultado el 20 de noviembre de 2019).

${ }^{13}$ Ver: "EZLN acusa que fue un engaño..." (2019).

${ }^{14}$ Es el caso de la Asamblea Informativa celebrada en Palenque, Chis. según el reporte de la Secretaría de Educación Pública que estuvo presente en esa etapa.

\section{Referencias}

Acuerdos de San Andrés (1996). "Documento l: pronunciamiento conjunto que el gobierno Federal y el EZLN enviarán a las instancias de debate y decisión nacional". México. Disponible en: https://www.ilo.org/ public/spanish/region/ampro/mdtsanjose/indigenous/ sandres.htm (consultado el 3 de enero de 2020).

Aguirre Beltrán, Gonzalo (1991). Obra antropológica, IX. Regiones de refugio: El desarrollo de la comunidad y el proceso dominical en Mestizoamérica. México: FCE, UV, INI, GEV. Boege, Eckart (2008). El patrimonio biocultural de los pueblos indígenas de México. Hacia la conservación in situ de la biodiversidad y agrodiversidad en los territorios indígenas. México: INAH/CDI.

Centro Fray Julián Garcés Derechos Humanos y Desarrollo Local A.C. (2019). iSabes qué es el Proyecto Integral Morelos? México: el Centro.

CCMSS (Consejo Civil Mexicano para la Silvicultura Sostenible) (2019). "Consulta Indígena sobre el megaproyecto Tren Maya incumple convenio 169 de la OIT; violaciones podrían judicializarse". México: CCMSS, $l 1$ de diciembre. Disponible en: https:// www.ccmss.org.mx/consulta-indigena-sobre-elmegaproyecto-tren-maya-incumple-convenio-169-dela-oit-violaciones-podrian-judicializarse/ (consultado el 3 de enero de 2020).

CFE (Comisión Federal de Electricidad) (2011). Proyecto Integral Morelos. CCC Centro y Gasoducto Tlaxcala-PueblaMorelos. México: CFE. Disponible en: http://em.fis.unam. mx/public/mochan/blog/20110803proyectoMorelos.pdf (consultado el 3 de enero de 2020).

CIDH (Comisión Interamericana de Derechos Humanos) (2009). Derechos de los pueblos indígenas y tribales sobre sus tierras ancestrales y recursos naturales. Normas y jurisprudencia del sistema Interamericano de 
derechos humanos. OEA/Ser.L/V/II. Doc. 56/09, 30 de diciembre. Disponible en: http://cidh.org/countryrep/ TierrasIndigenas2009/Indice.htm (consultado el 3 de enero de 2020).

CIDH (Comisión Interamericana de Derechos Humanos) (2015). Pueblos indígenas, comunidades afrodescendientes y recursos naturales: protección de derechos humanos en el contexto de actividades de extracción, explotación y desarrollo. OEA/Ser.L/V/II. Doc. 47/15, 31 diciembre de 2015.

CNDH (Comisión Nacional de Derechos Humanos) (2019). "Solicita CNDH a autoridades federales y estatales de Oaxaca y Veracruz otorgar medidas cautelares ante la consulta sobre el proyecto Corredor Interoceánico Istmo de Tehuantepec". Comunicado de prensa DGC/118/19, 30 de marzo.

Corte IDH (Corte Interamericana de los Derechos Humanos) (2007). Caso del Pueblo Saramaka. Vs. Suriname. Excepción Preliminar, Fondo, Reparaciones y Costas. Sentencia de 28 de noviembre. Serie C No. 172.

Corte IDH (Corte Interamericana de los Derechos Humanos) (2012). Pueblo indígena kichwa de Sarayaku vs. Ecuador. Resumen oficial emitido por la Corte Interamericana. Sentencia del 27 de junio de 2012 (Fondo y reparaciones).

Cruz Rueda, Elisa (2008). "Mecanismos de consulta a los pueblos indígenas en el marco del convenio 169 de la OIT: el caso mexicano". En Revista Pueblos y Fronteras Digital, 3(5), 74-1ll. Disponible en: http://www. pueblosyfronteras.unam.mx/index.php/index.php/pyf/ article/view/208 (consultado el 3 de enero de 2020).

"Decreto por el que se declara reformadas y adicionadas diversas disposiciones de la Constitución Política de los Estados Unidos Mexicanos, en materia de Consulta Popular y Revocación de Mandato" (2019). En Diario Oficial de la Federación, 20 de diciembre. Disponible en: http://dof.gob.mx/nota_detalle.php?codigo=5582486 Effecha=20/12/2019 (consultado el 3 de enero de 2020).

Espinoza Hernández, Raymundo (2019). “La consulta a debate ¿Garantía de derechos o mecanismo de despojo?". En Ecuador Debate, 106, 75-92.

"EZLN acusa que fue un engaño consulta del tren maya" (2019). En Riodoce, 20 de diciembre. Disponible en: https://riodoce.mx/2019/12/20/ezln-acusa-que-fueun-engano-consulta-del-tren-maya/ (consultado el 3 de enero de 2020).

Gasparello, Giovanna (2016) "Entre la Montaña y Wirikuta: defensa del territorio y del patrimonio cultural y natural de los pueblos indígenas". En Argumentos. Estudios críticos de la sociedad, 81, 221-240.

"Geopolítica de los megaproyectos Morelos-PueblaTlaxcala" (s/f). En jovenesenemergencia.org. Disponible en: http://jovenesemergencia.org/mapas/geopoliticamor-pue-tlax/ (consultado el 3 enero de 2020).

Giménez, Gilberto (2000). "Territorio, cultura e identidades: la región sociocultural”. En R. Rosales Ortega (ed.), Globalización y regiones en México. México: UNAM/Porrúa, pp. 19-33.

Gómez, Magdalena (2017). "Derecho indígena al territorio y a la consulta: el caso yaqui en México". En e-cadernos ces, 28, 141-164. Disponible en: https:// journals.openedition.org/eces/25ll (consultado el 3 de enero de 2020).

Gómez Godoy, Claudia, María de los Ángeles Arcos García y Tajín Villagómez Velázquez (2017). “Contrariedades de la justicia: la consulta indígena como espejo de desigualdad. Análisis crítico de tres casos en México" [manuscrito inédito]. Disponible en: https:// territoriosypatrimonio.files.wordpress.com/2018/04/ consulta-indicc8lgena-gomez-godoy.pdf (consulta el 3 de enero de 2020).

González Rojas, Aldo (2016). "Las consultas de la CONAFOR a comunidades indígenas para la Estrategia nacional de reducción de emisiones por deforestación y degradación (ENAREDD+)". En L. Hernández y A. de Ita (coords.), La nueva servidumbre agraria y la resistencia indígena y campesina. México: CECCAM, pp. 71-82.

Gutierrez Rivas, Rodrigo y Edmundo del Pozo Martínez (2019). De la consulta a la libre determinación de los pueblos. Informe sobre la implementación del derecho a la consulta y al consentimiento previo, libre e informado en México. México: Fundación para el Debido Proceso/Instituto de Investigaciones Jurídicas UNAM/Fundar. Centro de Análisis e Investigación A.C. 
Henríquez Ramírez, Alfonso (2013). "Participación indígena: desarrolloy alcances en torno a la participación ambiental". En Revista luset Praxis, 19(2), 25l-300.

Herrera, Analía (2019). "La vida no se consulta”. En OjarascaLa Jornada, 9 de marzo. Disponible en: https://ojarasca. jornada.com.mx/2019/03/09/el-proyecto-integralmorelos-y-la-nueva-consulta-ciudadana-6297.html (consultado el 1 diciembre de 2019).

INPI (Instituto Nacional de los Pueblos Indígenas) (2019a). "Gobierno de México escucha voces y planteamientos de los pueblos indígenas sobre el Programa de Desarrollo del Istmo de Tehuantepec". México: Gobierno de la República, 31 de marzo. Disponible en: https:/www.gob.mx/inpi/articulos/ gobierno-de-mexico-escucha-voces-y-planteamientosde-los-pueblos-indigenas-sobre-el-programade-desarrollo-del-istmo-de-tehuantepec-195797 (consultado el 3 de enero de 2020).

INPI (Instituto Nacional de los Pueblos Indígenas) (2019b). "Convocatoria y Protocolo para el Proceso de Consulta Indígena sobre el Proyecto de Desarrollo Tren Maya. Proceso de Consulta Indígena y Jornada de Ejercicio Participativo Ciudadano sobre el Proyecto de Desarrollo Tren Maya”. México: Gobierno de la República, 15 de noviembre. Disponible en https://www.gob.mx/inpi/ documentos/convocatoria-al-proceso-de-consultaindigena-sobre-el-proyecto-de-desarrollo-trenmaya?idiom=es (consultado el 3 de enero de 2020).

Leyva Hernández, Alejandra et al. (2018). Guía para el uso y monitoreo de los procesos de consulta a pueblos y comunidades en contextos de megaproyectos en México. México: Centro Mexicano de Derecho Ambiental y Fundar, Centro de Análisis e Investigación. Disponible en: http:// fundar.org.mx/wp-content/uploads/2018/10/Guia_de Consulta-web.pdf (consultado el 3 de enero de 2020).

Lins Ribeiro, Gustavo (1987). “¿Cuánto más grande mejor? Proyectos de gran escala: una forma de producción vinculada a la expansión de sistemas económicos". En Desarrollo Económico, 27(105), 3-27.

Llaven, Yadira (2019). "Determina tribunal que es procedente amparo contra la consulta del gasoducto Morelos". En La Jornada de Oriente, 16 de mayo.
Disponible en: https://www.lajornadadeoriente.com. mx/puebla/amparo-consulta-gasoducto/ (consultado el 2 de enero de 2020).

López Bárcenas, Francisco (2013). El derecho de los pueblos indígenas de México a la consulta, Oaxaca: Servicios para una Educación Alternativa A.C.

Murayama, Ciro (2019). "El INE y la consulta de Huexca". En El Excelsior, 19 de febrero. Disponible en: https:// www.excelsior.com.mx/opinion/opinion-del-expertonacional/el-ine-y-la-consulta-de-huexca/1297244 (consultado el 3 de enero de 2020).

Murcia Riaño, Diana Milena (2019). "La participación de los pueblos indígenas y tribales en medidas administrativas con impacto en el territorio". En Ecuador Debate, 106, 57-73.

Núñez, Efraín (2019). "Puebla, el estado con menos aceptación al gasoducto Morelos". En e-consulta. com, 25 de febrero. Disponible en: https://www.econsulta.com/nota/2019-02-25/sociedad/puebla-elestado-con-menos-aceptacion-al-gasoducto-morelos (consultado el 1 diciembre de 2019).

ONU-DH (Oficina en México del Alto Comisionado de las Naciones Unidas para los Derechos Humanos) (2019). México: ONU-DH, 19 de diciembre. "El proceso de consulta indígena sobre el Tren Maya no ha cumplido con todos los estándares internacionales de derechos humanos en la materia". Disponible en: https://www.hchr.org.mx/index.php?option=com k2\&view=item\&id=1359:onu-dh-el-proceso-deconsulta-indigena-sobre-el-tren-maya-no-hacumplido-con-todos-los-estandares-internacionalesde-derechos-humanos-en-la-materia\& Itemid=265 (consultado el 3 de enero de 2020).

OIT (Organización Internacional del Trabajo) (1989). Convenio núm. 169 de la OIT sobrepueblos indígenas y tribales en países independientes. C169. Disponible en: https:// www.ilo.org/dyn/normlex/es/f?p=NORMLEXPUB:1 2100:0::NO::P12100_ILO_CODE:C169 (consultado el 3 de enero de 2020).

Presidencia de la República (2019). "Versión estenográfica. Presentación de la propuesta para la termoeléctrica en Huexca". México: Gobierno 
de la República. Disponible en: https://www. gob.mx/presidencia/es/articulos/mensaje-delpresidente-andres-manuel-lopez-obrador-en-cuautlamorelos? idiom=es (consultado el 1 diciembre de 2019).

"Proposición con punto de acuerdo, por el que se exhorta al Ejecutivo federal a hacer del conocimiento público por el director general de la CFE los efectos sociales, económicos y ambientales del Proyecto Integral Morelos, en perjuicio de los pobladores de ese estado, de Puebla y de Tlaxcala" (2013). En GacetaParlamentaria, núm. 3746-VII, ll de abril. Disponible en: http://gaceta. diputados.gob.mx/Black/Gaceta/Anteriores/62/2013/ abr/201304ll-VII/Proposicion-27.html (consultado el 3 de enero de 2020).

Proyectos México Oportunidades de Inversión (2019). "Macroproyecto Programa de Desarrollo del Istmo de Tehuantepec". México. Disponible en: https://www. proyectosmexico.gob.mx/proyecto_inversion/programapara-el-desarrollo-del-istmo-de-tehuantepec-pdit/ (consultado el 2 de enero de 2020).

ONU (Organización de las Naciones Unidas) (2007). Declaración de la Naciones Unidas sobre los Derechos de los Pueblos Indígenas.

Rodríguez, Nemesio (2000). "Un sueño cortesiano: el Istmo de Tehuantepec". En Estado del desarrollo económico y social de los pueblos indígenas de México. Primer informe. México: INI/PNUD, pp. 185-188.

Rodríguez, Nemesio (2003). Istmo de Tehuantepec. De lo regional a laglobalización (o apuntes parapensar un quehacer). Oaxaca: Secretaría de Asuntos Indígenas/Gobierno del Estado de Oaxaca.

Rodríguez Garavito, César (2012). Etnicidad.gov. Los recursos naturales, los pueblos indígenas y el derecho a la consulta previa en los campos sociales minados. Bogotá: Centro de Estudios de Derecho, Justicia y Sociedad.

"Sánchez Cordero contradice a AMLO: consulta sobre el NAIM no es vinculante ni legal" (2018). En Animal Político, 25deoctubre. Disponibleen:https://www.animalpolitico. com/2018/10/consulta-aeropuerto-vinculante-legalsanchez-cordero/ (consultado el 16 de febrero de 2019).

Santos, Boaventura de Sousa (2005). "Beyond Neoliberal Governance: The World Social Forum as Subaltern Cosmopolitan Politics and Legality". En Boaventura de Sousa Santos y César Rodríguez Garavito (eds.), Law and Globalization from Below: Towards a Cosmopolitan Legality. Cambridge: Cambridge University Press.

SCJN (Suprema Corte de Justicia de la Nación) (2017). 2013976. I.8o.C. J/2 (10a.). Tribunales Colegiados de Circuito. Décima Época. Gaceta del Semanario Judicial de la Federación. Libro 40, marzo de 2017, p. 2416.

Tauli-Corpuz, Victoria (2019). "Nota técnica sobre la consulta y el consentimiento libre, previo e informado de los pueblos indígenas en México (febrero de 2019)". Ginebra: ONU. OL MEX 2/2019, 5 de marzo. Disponible en: http://unsr.vtaulicorpuz.org/site/ index.php/es/documentos/special/278-nota-tecnicaconsulta-mexico (consultado el 2 de abril de 2019).

Torres Fragoso, Jaime (2017). "El corredor del Istmo de Tehuantepec: de los proyectos fallidos a las nuevas posibilidades para su desarrollo". En Espacios Públicos, 20(48), 127-149.

"Tren Maya iría a consulta en 16 municipios de Yucatán" (2019). En La Jornada Maya, 25 de marzo. Disponible en: https://www.lajornadamaya.mx/2019-03-25/TrenMaya-iria-a-consulta-en-16-municipios-de-Yucatan (consultado el 3 de abril de 2019). 